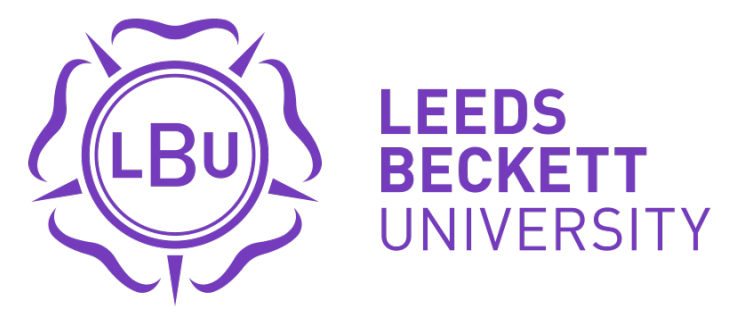

Citation:

Gough, B and Milnes, K and Turner-Moore, T (2019) Young masculinities across five European countries : performing under pressure. Journal of Youth Studies. ISSN 1367-6261 DOI: https://doi.org/10.1080/13676261.2019.1695763

Link to Leeds Beckett Repository record:

https://eprints.leedsbeckett.ac.uk/id/eprint/6452/

Document Version:

Article (Accepted Version)

This is an Accepted Manuscript of an article published by Taylor \& Francis in Journal of Youth Studies on 27 Nov 2019, available online: http://www.tandfonline.com/10.1080/13676261.2019.1695763

The aim of the Leeds Beckett Repository is to provide open access to our research, as required by funder policies and permitted by publishers and copyright law.

The Leeds Beckett repository holds a wide range of publications, each of which has been checked for copyright and the relevant embargo period has been applied by the Research Services team.

We operate on a standard take-down policy. If you are the author or publisher of an output and you would like it removed from the repository, please contact us and we will investigate on a case-by-case basis.

Each thesis in the repository has been cleared where necessary by the author for third party copyright. If you would like a thesis to be removed from the repository or believe there is an issue with copyright, please contact us on openaccess@leedsbeckett.ac.uk and we will investigate on a case-by-case basis. 


\title{
Young masculinities across five European countries: Performing under pressure
}

\begin{abstract}
We present an analysis of young masculinities based on young peoples' perspectives derived from a project on sexual bullying. Our qualitative data are based on 41 focus groups with 253 young people (male and female) aged 13-18 across five European countries (Bulgaria, Italy, Latvia, Slovenia and England) as well as questionnaire responses. The data were analysed using thematic analysis (Braun \& Clarke, 2006). Our analysis pointed to the prevalence of sexist and homophobic behaviours among young men, who were themselves concerned with their 'masculine' reputations by appearing physically tough, (hetero)sexually active and emotionally closed. The young women in our sample also depicted many young men as immature, naïve and superficial. At the same time, the young men were portrayed as more calm, rational and resilient compared to their female counterparts, with young men insisting that any 'problematic' or 'bullying' behaviour amounted to harmless fun. Our analysis suggests that young men are performing gender and sexuality under the influence of conventional norms which prioritize homosociality, humour and status, which shy away from challenging sexist or homophobic practices, and which inhibit reporting themselves as victims of bullying. The implications for young masculinities and social change are discussed.
\end{abstract}

Keywords: Masculinities; Sexual Bullying; Heteronormativity; Homophobia; Sexism

\section{Introduction}

Gendered cultures pertaining to settings where young people are located, including educational spaces, have been highlighted in various qualitative research projects (e.g. Renold, Bragg, Jackson \& Ringrose, 2017; Carrera-Fernandez, Lameiras-Fernández \& Rodríguez-Castro, 2018). Specifically, traditional norms are seen to regulate young people's practices, positioning male and females as essentially different and reinforcing performances of hegemonic masculinity which aspire to dominance over females and male peers (e.g. Adams-Tucker \& Govender, 2017). While complexities and contradictions have been noted in the construction of young masculinities (e.g. Frosh, Phoenix \& Pattman, 2001), with some authors emphasising alternative, more inclusive forms of masculinity among young men (e.g. Anderson, 2009; Swain, 2006), the overriding theme points to the continued influence of hegemonic masculinity on young men's self-presentation. Building on this work, this paper reports on a study involving young people across five European countries where gender featured prominently in young people's accounts of everyday life. The specific focus of the project was on 'sexual bullying', which allowed us to explore young peoples' perceptions, stories and practices concerning interactions and relationships with male and female peers.

While there is debate about the extent to which boys and young men can access hegemonic masculinity (see Bartholomaeus, 2013), various qualitative studies have elucidated the strategies that young men deploy in order to attain (masculine) status. For example, Renold et al. (2017) report on boys' judgement and rating of girls based on their appearance, their positioning of males as active and females as passive, and their attachment to a sexual double standard where sexual activity is praised in boys and critiqued in girls. In the Carrerra-Fernadez et al. (2016) study, 'performing intelligible 
masculinity' consists of fights between boys, with 'abuse' often framed as banal, or even appreciated by peers. Humour features strongly in several studies, with young men downplaying physical and verbal aggression, citing a lack of intent, unanticipated harm and innocent fun (e.g. Adams-Tucker \& Govender, 2016). Another theme relates to the 'othering' of boys perceived to be different through homophobic or 'faggot' discourse (Pascoe, 2013), a means of bolstering masculinity via emasculating particular male peers. These and other studies have also identified sexual bullying and harassment online. For example, we know that young men are involved in a range of sexual bullying practices online, including unsolicited sexting (Ringrose \& Harvey, 2015; Yépez-Tito, Ferragut \& Blanca, 2019) and homophobic bullying (Rivers, Chesney \& Coyne, 2011). The work of Powell, Henry and Flynn (2018) provides a useful overview of the gendered nature of 'image-based sexual abuse' online, highlighting that men engage in such acts more than women and that the impact of this abuse can be devastating for women, often accentuated by victim-blaming. Overall, these qualitative studies favour an analysis of 'bullying' as context-bound, socially situated and gendered rather than a phenomenon residing within certain individuals ('bullies') with a tendency to target 'victims'.

The studies cited above have taken place within specific school, community and national contexts, largely Anglophone, with the exception of Carrera-Fernandez et al. (Spain) and AdamsTucker \& Govender (South Africa). We know little about manifestations of changing young masculinities in different European contexts, especially in Eastern and Southern European countries, and our study provides an opportunity to examine similarities and differences across five countries (Bulgaria, England, Italy, Latvia and Slovenia). In addition, (young) women's perspectives on masculinities have been under-researched (see Quayle et al., 2018), which is curious in light of theoretical emphasis on masculinities/gender as co-produced; indeed, Connell and Messerschmidt (2005: 848) argue that 'hegemonic masculinity now needs to give much closer attention to the practices of women'. Our project has collected data on young women's perspectives on gender, sexual bullying and peer relationships, offering another dimension to research on young masculinities. Like other qualitative projects, our study prioritises the voices of young people, asking open questions, encouraging debate (in focus groups) and eliciting personal stories (via qualitative questionnaires). Given the focus of the project on sexual bullying, we anticipated constructions of young masculinities along hegemonic, heteronormative lines while being open to instances of resistance to and rejection of such norms.

\section{Methodology}

The ASBAE (Addressing Sexual Bullying Across Europe) project was funded by the EU Daphne III programme (which aims to protect children, young people and women against all forms of violence). We aimed to elicit young people's definitions and accounts of sexual bullying, as well as their suggestions for effective interventions. The project was led by a research team from an English university and included partners from NGOs in Bulgaria, England, Latvia, Slovenia and Italy. The project adopted a participatory action approach: a Young People Advisory Group (YPAG) was set up in each of the five countries, each comprising approximately six young men and young women aged $13-18$ years, tasked with providing us with locally relevant input and feedback on each stage of the project over the two-year period. Each partner was involved in the design, implementation and analysis of the research, providing input and feedback at every stage.

We gathered data from young people via focus groups (eight/nine in each country $=41$ groups) and questionnaires. Over the five countries, 253 young people participated. This included 
approximately equal numbers of young women ( $n=125 ; 49 \%)$ and young men ( $n=128 ; 51 \%)$. The average age of the participants was $15.27(S D=1.64)$, including four participants below the target age range of 13-18 year-olds (four 12 year-olds) and two participants above the target age range (one 19-year-old and one 20-year-old). Participants most commonly identified as being White (86\%), though other ethnicities were represented (8\% Black, 5\% Asian, 2\% Mixed). Nearly threequarters of the sample were Christian (71\%), with the remainder, Muslim (11\%), Sikh (<1\%), Other $(1 \%)$ or with no religious affiliation (17\%). Nearly all (98\%) were in school, training or other education and $4 \%$ were in paid employment. The majority identified as being attracted to different sex people (96\%) and a minority identified as being attracted to same sex people (2\%) or both different and same sex people (2\%); a quarter (26\%) of the participants were currently in a relationship. Three-quarters (74\%) of the participants lived in an urban area.

Participants for nearly half of the focus groups (46\%) were recruited from schools/colleges, with the remainder recruited from youth centres $(27 \%)$, non-governmental organisations $(17 \%)$ and other organisations (e.g. volunteer firefighters' brigades, football clubs: 10\%). With the exception of two focus groups, the groups were single sex. The Italian, Slovenian and Latvian samples were recruited from both urban and rural areas, whereas the Bulgarian and UK samples were predominantly from urban areas.

The focus groups typically took place in a private room at the recruitment venue and were scheduled to avoid busy times for young people (e.g. exam periods). The focus groups ran for an average of 151 minutes ( 2.52 hours; $S D=36.52$ minutes), including breaks and time to complete the questionnaire. The focus groups were undertaken by an average of two adult facilitators from the partner organisations; $54 \%$ of focus groups included only female facilitators and $46 \%$ of focus groups included both female and male facilitators.

The focus group discussions used a schedule of discussion items which were arranged into three topic areas: peer relationships, awareness of sexual bullying, and suggestions for prevention. The discussion of these three topics was interspersed with other activities to try to ensure that the young people did not grow tired of the discussion and to provide examples of sexual bullying scenarios to stimulate further discussion. For example, various media clips were presented, taken from a range of UK/Irish anti-bullying and abuse campaigns and US films. The video clips we used covered a range of issues, including online and offline forms of slut-shaming and homophobic bullying, circulation of sexual images without consent and putting pressure on someone for sex.

Between focus group topics two and three, the young people individually completed a questionnaire about their experiences of being subject to and also of enacting sexual bullying. To facilitate private completion of the questionnaire, tables and chairs were spaced out around the edges of the room so that each young person could complete the questionnaire without fear of being overlooked. The Sexual Bullying Questionnaire comprised three sections: the demographic characteristics of the participants, their victimisation experiences, and finally, their experiences of instigating sexual bullying behaviours. The questionnaire was structured so that the least sensitive section was presented first (demographics) and the (possibly) most sensitive section was presented last (instigating sexual bullying acts). The questions covered in the demographic section were the same across all five countries, although the response options for some questions varied (i.e. nationality and ethnicity). For the qualitative sections of the questionnaire (relevant for this paper), participants were presented with a series of open-ended questions and invited to choose aspects of sexual bullying that they had experienced and to describe, in as much detail as possible, what happened, as if they were writing an entry in a diary or blog. 
Ethical issues relating to the research were discussed in depth with partners. This included potential risks to participants and how these would be addressed, confidentiality and anonymity, how to ensure participation was voluntary, obtaining informed consent, provisions for the withdrawal of data, the storage and destruction of data, risks to researchers and country-specific laws and issues. Ethical approval was gained from the relevant university ethics board prior to any data collection.

The focus group discussions were all digitally recorded with participants' permission and then transcribed and anonymised. The focus group transcripts and questionnaire accounts were translated into English (where required) and initially coded with the help of NVivo (version 11) using inductive thematic analysis (Braun \& Clarke, 2006). A comprehensive thematic analysis of the whole dataset was first completed before the first author developed a focused analysis on themes and data relevant to young masculinities. The approach was broadly constructionist i.e. sensitive to the 'performative' aspects of talk/text (i.e. using words to perform actions such as the positioning of self and others) and to wider social norms (e.g. around gender and sexuality) which shape and constrain such talk.

\section{Findings}

We identified three key themes relating to young masculinities which predominantly highlight forms of male harassment against young women and men, both online and face-to-face, including sexual harassment and homophobic policing. Generally, the examples presented refer to peers known to the young people rather than young men or women in general. However, this 'toxic' masculinity was to some extent resisted by young people, who presented various 'problematic' practices as lighthearted performances that were constructed as jokes, misplaced affection, or (sometimes) as a developmental phase or the result of puberty. These themes are elaborated below.

\section{Peer-oriented performances of sexual harassment}

In general, young men were construed as pests by their female counterparts, fixated on sex and prone to physically and verbally harass young women within and beyond school settings in conjunction with, or with an audience of, male peers:

When I was in the elementary school, the boys stood behind me and pulled my bra, making derogatory comments like how much better you will feel if you sleep with them [FGB \{Focus Group Bulgaria\}, 1: Female; age 13-15]

There is this girl right who has large body features and the boys sometimes shout at her 'Double D'.

[FGE \{Focus Group England\}, 4: Female; age 13-15]

Having male friends, they act a bit like '"pigs" and they begin to touch me against my will. Whatever I say, they do not stop. Not only my friends touch me. People say that I have a nice butt. Then many try to unhook my bra and many times they succeed ... Finally, they call me lesbian just because with my closest friends we kiss on the mouth.

[QI \{Questionnaire Italy\}, 19: Female; age 17]

This last quote illustrates how, at least for certain periods of time, this kind of sexual harassment can become relentless. In general, young men were described as deploying direct verbal comments, gestures and touching, with young women's bodies and particular body parts (e.g. breast, bottom) 
the main focus.

Particular circumstances can also facilitate such sexual objectification, for example in physical education classes:

We had sports day in primary school and my friend (female) had really tight sport pants so you could see the 'line' of her vagina. One boy spotted that and started to point at it with his finger and make jokes. Also, other boys started to make jokes about it and she felt really not-comfortable and embarrassed.

[QS, \{Questionnaire Slovenia, 12: Female; age 15] My good friend thinks it's funny to take pictures of girls during gym classes, when they don't wear their bra. He has already posted and tagged some girls on Facebook with their nipples clearly seen.

[QS, 31: Male; age 16]

Further, sex was actively pursued as an achievement and source of status by young men:

A certain boy would ask for sex despite the fact he had a girlfriend - constant persistence of messages and requests for photos. Sexual comments on streets by groups of people. Inappropriate touching from boys often humping, thrusting, touching or 'jiggling' breasts, in awkward times when not wanted

[QE, 14: Female; age 16]

In this questionnaire response, a girl lists various forms of unsolicited sexualized attention she has experienced, ranging from blunt requests for sex to the performance of mock sexual acts on and around her body. The importance of a peer audience for such displays, whether physically present or online, was emphasized:

Basically I think the guy wants it because he wants to get ratings from his friends but when the girl does she is going to get called a whore and stuff like that, because guys and girls are different in this kind of like sexual way, because the guy is like 'oh my god I had sex and blah blah blah' and the girl is just like 'oh you're such a 'sket' you slept with him blah blah blah' but it happens.....

[FGE, 2: Female; age 13-15]

One of my friends sent a picture of his girl naked. He is boasting how he had her on his demand. And that he can get any girl. He spread rumours about how she had sex with him and performed multi types of oral sex

[QE, 49: Male; age 18]

Such sexual objectification of young women via social media was widely reported, where images of young women were uploaded, embellished, shared and subject to comments by young men. Many examples are cited where formerly private content was made public by young men. Personal information, whether fabricated or authentic, may be uploaded and distributed widely, creating a new phenomenon which is painful and difficult to counter. For example, 'private' text conversations may be captured and posted online by young men without the (female) victim's knowledge:

A girl once had had a conversation via text message with a guy, covering another boy she liked, the boy then took a picture of the conversation by posting it to Facebook so that everyone could read it 
In fact, the private conversation does not have to be recorded - a version of the discourse can simply be constructed by young men and posted online for all to see:

I've known a boy who I am acquainted with, him and my friend who is a female used to talk to each other a lot. One day the girl decided to tell him of the things she had done with other boys and out of disgust the boy repeated everything she has said to him in confidence on social media. Everyone has, at one point, seen the messages of my female friend's sexual activity. This had effectively demoralised her. However in the end the boy was seen as a fool who was acting on desperation and the girl was supported by everyone

[QE, 51: Male; age 17]

The online world also provides young people with a set of challenges. For example, young men may pester their female peers on social media for sexual activity:

I think sexual bullying like among peers isn't just like in school and stuff if it also continues again to social networks like a lot of the time I think you can, like a lot of the boys in our year asked for sexual [contact] like from me or from peers and you can tell that's not right but because it's on social media you don't really know how to like say go away. Usually I will just blank things like that and I don't even have Facebook. That's one of the reasons why I don't have Facebook or Twitter because of guys like that that just like labelise you, like even if it's just your picture or anything they just like think you are easy or whatever.

[FGE, 3: Female; age 16-18]

In addition to name-calling, receiving unsolicited requests (e.g. for naked photographs) from unknown boys online was mentioned; one young woman highlights unsolicited sexting, for example when a boy's phone is commandeered by his male peers:

My (male) school mates often steal each other phones and then send text messages to girls in the phone book with sexual content: mostly they write about girl's breasts and bottoms.

[QS, 16: Female; age 14]

Young men may also share young women's phone numbers with each other, which may encourage multiple sexting episodes, as one young woman describes:

I gave my number to a schoolmate because we had to prepare a seminar together, and he gave my number to his friends at handball club. They were sending me text messages with sexual content and invitations for a long time.

[QS, 10: Female; age 16]

Blackmail was mentioned frequently with regards to images and videos:

If he took a picture of you and he blackmails you. If he took a picture of you in an inappropriate position and he threatens you that he would spread the photos if you don't do something

[FGB, 7: Female; age 16-18]

Online sexual bullying may also entail uploading and spreading faked images, which can then lead to further attention and comments: 
There is this programme on the internet where you can put pictures of someone's face to body parts of famous persons so my schoolmate put my face to the body of Pamela Anderson, this chick from Baywatch and posted it on Facebook, and tagged me in [it]. The picture got many comments, especially from boys, saying: uhh, and $\mathrm{mmm}$, and commenting on the big breasts and so on. [QS, 23: Female; age 14]

In this questionnaire account, the female victim is sexualized via a manufactured image posted on social media by someone she knew, which subsequently generates objectifying posts from young men. Alternatively, online profiles and current 'statuses' may be 'hacked' and sexualized content uploaded maliciously:

In primary school [it] often happened that the guys hacked Facebook (usually girls' profiles). They wrote the various statuses related to sexuality and their bodies

[QS, 9: Female; age 16]

From the above extracts it is clear that technology is used mostly by young men to pressurize and victimize young women. Overall, young men were painted as prone to various forms of sexual harassment often conducted in the presence (physical or digital) of - or recounted/reproduced for the benefit of - their (male) peers, thereby acquiring peer approval and reinforcing restrictive masculinity norms. In so doing, the young men pursued access to a version of hegemonic masculinity which relies on homosociality, heternormativity and the subordination and objectification of young women, as highlighted by other researchers (e.g. Renold et al., 2017; Ringrose \& Harvey, 2015).

\section{Homophobic (self-)policing}

The focus groups indicated that homophobic bullying was a problem among young people, with young men cast as the main culprits by young women, and through their own talk. In general, there was less tolerance of peers labeled as 'gay' (notably young men) in the younger age groups (13-15), and in rural groups. When tolerance was expressed, it tended to be conditional (e.g. on discretion) with elements of homophobia remaining (e.g. heterosexuality implied as natural/normal) in the young men's accounts, while young women generally expressed acceptance with few or no caveats.

Although the term 'lesbian' was occasionally invoked as a term of abuse (e.g. towards young women who did not dress in conventionally 'feminine' ways or who rejected a young man's advances), for the most part lesbian young women were not problematized - in contrast to young men known to be - or perceived to be - gay:

I'm going to be honest - if you're a lesbian in my school all the boys love you because lesbians are like a hot thing if you're a boy (laughter). It's true! But if you're a guyoh my God I feel sorry for you please come to me, I will hug you. Like stuff like, boys like have to put up with just for even appearing to be gay - all the grief they get I just think, no not fair.

[FGE, 2: Female; age 13-15]

As these young women pointed out, male homosexuality, whether a known status or merely presumed from another's appearance or behaviour, was typically denounced by young men they knew, who were prone to bully certain peers (give them 'grief') while they (young women) exuded a more sympathetic attitude ('I will hug you'). Criteria for 'gay' behaviour tend to converge on those practices deemed feminised. 
And like, some boys behave more like girls, or just act differently, and they are often getting called, hey you queer, and never, I don't know Luka. I think this is also bullying.

[FGS, 4: Female; age 13-15]

So, those perceived to be acting in feminised ways were positioned as 'gay' and subjected to harassment. Young men may also be castigated as 'gay' if perceived to lack the appropriate amount of sexual experience:

My brother once got in a fight with one guy because he said to him that he is gay, because he still didn't have any girlfriend and hadn't had sex so far.

[QS, 19: Female; age 14]

Young men's orientation to heterosexual masculinity also meant that being targeted by women was considered to be especially problematic, with any pain experienced to remain unreported:

I was constantly pinched by my (female) neighbour who is 3 years older, and she was calling me names like "little one" all the time. She knew I wasn't going to tell anyone about it because she is a girl, but I got bruises on my hands and back because of it. I really hated when she did that.

[QS, 38: Male; age 15]

Relatedly, being a victim at the hands of any peer for young men was to inhabit a feminised or 'gay' position, and therefore to be avoided or at least minimised:

Actually I think the main bullying like that face to face like pick on and start on someone and they just carry on for a long period of time and then yeah cos that one is more of an intense thing because I've never been bullied personally but I can imagine if I was in that moment I wouldn't feel like, I wouldn't feel like me cos I'd feel weak because I am letting someone pick on me but then in reality you are actually stronger than that person is. That person is doing it for a reason cos they most likely either got bullied or something is going on in their life that they are trying to take it out on you and they want you to feel half of what they feel. [FGE, 5: Male; age 1315]

We also noted that self-reliance is valued by young men - a commitment to coping independently. Emotions are not something to be experienced, or at least acknowledged by males, to such an extent that an invitation toward male emotional disclosure is treated humorously:

Participant 1 (P1): I think it's also harder to hurt boys, or we keep it for ourselves. Vid, you know you can always come cry on my shoulder, right?

All: $\quad$ (Laughter)

[FGS, 9: Males; age 13-15]

In this context where deviation from heteronormativity can easily attract censure for young men, male homosexuality was often subject to condemnation:

P1: $\quad$...That boy had a different orientation.

Mentor: Have you never spotted something like that in the streets? 
P1: $\quad$ To be honest I haven't. But I think that it is not right.

[FGL, 2: Male; age 13-15]

It is important to point out, however, that homophobic talk was sometimes challenged by young men, for example:

if you live in the UK and the UK says that people are allowed to be who they are, go on the streets and kiss guys if they want to kiss guys, so it is up to them. I don't think that they have to hide.

[FGE, 8: Male; age 16-18]

Overall, young men in the focus groups (and those referenced by young women) were evidently invested in heteronormativity and the surveillance of self and others for signs of supposedly 'gay' practices, which were mercilessly mocked and punished. The othering of people or practices deemed to be nonheterosexual evidences a preoccupation with maintaining hegemonic masculinity, as other researchers have noted with communities of boys and young men (e.g. Pascoe, 2013; Rivers et al., 2011).

\section{Downplaying and denying bullying accusations}

Young men in particular were often regarded as engaging in sexual bullying for reasons of entertainment - the behaviour was seen as a 'joke' rather than something which could impact negatively on another:
P1:
Some do it just to have fun. So they can laugh about someone.
MENTOR:
As a joke?
P2:
They simply have too much time.
[FGL, 6: Female; age 13-15]

Acts of sexual bullying are often interpreted by young men as attempts to generate humour or relieve boredom. Although the chosen victim may not enjoy being targeted, the young man's intentions are not thought to be malicious:

Some like it, if you mention their tits, for example, and some feel unpleasant. Same with gays. Sometimes you jokingly tell someone, shut up you faggot, and don't mean anything bad by it.

[FGS, 9: Male; age 13-15]

Again, the nature of the remarks was tied to gender or sexuality, and here it is alleged that some victims will be pleased with the attention, thereby diverting responsibility away from the young $\mathrm{man} / \mathrm{men}$ involved; in any case the name-calling was presented as a 'joke'. Generally, young men known to the young women were portrayed as unaware of the potential impact such ostensibly 'innocent' behaviour can have (on young women):

Obviously the boys don't see it that way but to her that's just hitting a nerve. So they might not even know that it's bothering her

[FGE, 1: Female; age, 16-18] 
This account ties in with sex difference discourse which constructs young men within peer groups as direct and immature and young women as sensitive and emotional - and more likely to present themselves as victims, as two participants in this focus group suggest :

I think girls are victims more than boys. Boys don't take offence, they consider these acts like a joke...

Boys play down and they don't get angry. Girls get angry even if it's a joke.

[FGI, 4: Male; age 13-18]

Sometimes, this perceived tendency of male peers towards humour was presented positively:

P1: I think guys are more like freethinkers than girls are. Girls tend to worry about everything... they reason more, guys take everything easier.

P2: I I agree with Marta, because I think guys don't worry so much about the small stuff, while girls tend to remember every single word that had once been said; they will reflect on it and worry if they think something's not right. Guys will forget it after a short period of time; they don't stick to the small things.

[FGL, 7: Female; age 16-18]

The propensity to laugh at or dismiss situations otherwise viewed as sexual bullying by male peers is here glossed as a positive, as if young women overreact when confronted with 'clearly' light-hearted behaviour.

The 'joke' explanation also extends from verbal to physical instances e.g. young men touching their male peers 'for a laugh':

P1: It seems the same to me, this touching.

P2: $\quad$ This is pretty popular now, yes, especially amongst boys, but more out of joke.

Mentor: You consider it as a joke?

P2: $\quad$ Yes, not half of the class is queers.

[FGS, 6: Male; age 16-18]

Conversely, in cases where young men focus their (sexual) interest on young women, the young men excused it on the grounds of misplaced affection:

P1: I was at camp, right? And a boy had that laser, the pointer, right? And a girl came by and he pointed at her, right? At her ass, right? And she told him "Why are you doing this? Stop". And he said, "but this is good, there's nothing wrong with it". He didn't want anything bad, he was trying to say that he really likes her

[FGS, 3: Female; age 16-18]

Mentor: In your opinion, why does sexual bullying take place? What's the reason for that?

P2: $\quad$ Maybe I can start. It may be affinity and the group instinct. It's affinity if he goes to a girl and, for example, thrashes her on the bottom or gropes her boobs or stuff...it's just an example. It's how he shows her he likes her, pays 
more attention to her. But, if it's a group instinct, then he just does what everybody else is doing. The rest, for example, thinks of a disgusting nickname and everybody goes with it, for instance, calls her that; nobody wants to really go to her and thrash her on the bottom, but rather stand, like, 3 metres away from her and shout something disgusting at her or so.

P3: I think the problem is that this person can't find another way to express his emotions. He can't say "I like you" and so on. He tries to find other ways. And for most of the time sexual bullying is this way. Like, thrash on the bottom and so.

[FGL, 3: Male; age 16-18]

Again, we see that young men are positioned as sexual subjects and young women as sexual objects, with young men largely exonerated for any sexual gestures or touching. Further examples from young men's questionnaire responses suggest some insight into the impact of their behaviour:

I touched a girl's boobs once, it was dark, we were at a bus on the field trip, I thought she will like it but she didn't.

[QS, 36: Male; age 16]

It happened in the party where we were celebrating [a] friend's birthday. I made one girl feel uncomfortable because I thought that she likes me. I asked her to dance and while we were dancing I squeezed her close to me. She did not like that.

[QL, 11: Male; age 17]

To some extent, this sexualized behaviour is glossed as a developmental phase; the young people often contrasted their behaviour when younger with a more mature perspective in the present:

Yes, in the school we weren't mature enough, we were teasing someone, especially in the lower grades. And boys were frequently like pinching or tugging young women, because they didn't know how to behave.

[FGS, 1: Female; age 13-15]

For young men in particular, who are regarded as more provocative and immature, there is a widespread assumption that their behavior is tied to involuntary physiological changes associated with puberty, as two young women note:

I think when puberty kicks in - I mean not about the various stages - once those hormones kick in, boys like - the testosterone...

[later]

You see the way she said 'control your sexual desires' - you can't entirely control it. For example boys - if you were to walk past them and just go like that, they could get an erection - I'm just saying you can't entirely control it like that.

[FGE, 2: Female; age 13-15]

So, young people may be assuming that young men are at the mercy of their hormones in responding to young women in sexual ways - as a result, choice, control and responsibility are believed to be diminished. Overall, our young men and women agreed that males were prone to 
construe 'sexual bullying' as light-hearted, while females were likely to overreact in some situations: a sex difference discourse which clearly underplays young men's accountability. This downgrading of actions otherwise viewed as sexual bullying has been identified by other researchers (e.g. AdamsTucker \& Govender, 2016; Carrerra-Fernandez et al, 2016) and clearly works to legitimise performances of hegemonic masculinity.

\section{Discussion}

Our analysis supports other qualitative research on young masculinities and sexual bullying which highlight the ongoing influence of hegemonic masculinity for boys and young men, at least publically within peer groups (e.g. Renold et al., 2017; Carrerra-Fernandez et al., 2018; Adams-Tucker \& Govender, 2016). Specifically, our male participants were seen to actively or complicitly endorse an expression of masculinity which tightly conforms to a conventional 'hegemonic' configuration defined by sexism and homophobia (e.g. Connell, 1995): to deviate from traditional gender scripts is to be demonised while women are treated largely as sexual objects.

The defence often espoused, mainly by our young men, constructed such acts of 'bullying' as playful or harmless, without malicious intent (see also Carrerra-Fernandez et al., 2016). While the young men were prone to minimising the seriousness of their activities, presenting their female peers as rather dramatic and sensitive, Marwick and Boyd (2014) consider the ways in which such 'drama' associated with young women's (online) practices works to reinforce heteronormative scripts (see also Adams-Tucker \& Govender, 2016) - the young women at times lamented the immaturity and naivety evidenced by young men's behaviour. This immaturity was inherently timelimited, for example linked to puberty, with the prospect of bullying diminishing with age. The emphasis for young men on 'having a laugh' and being 'cool' can perhaps be linked to the reluctance to report personal experiences of bullying - a sign of weakness within the local masculine economy (see Harger, 2016; Ringrose \& Renold, 2010). At the same time, this inclination by young men to downplay or dismiss instances of sexual bullying was given a positive spin at times, where males were constructed as relaxed and rational - in contrast to their reactive and emotional female peers. In addition, the importance of (male) peers for endorsing and reinforcing young masculinities chimes with hegemonic masculinity theory (Connell, 1995) where homosociality and approval by other men is deemed crucial for legitimating masculine identity.

Our research then supports and extends other work which highlights the continued power of heteronormative scripts and pressures on young people especially within school and related contexts (Kehler \& Atkinson, 2015; Ringrose, 2010; Frosh et al., 2001), and including online practices (e.g. Ringrose \& Harvey, 2015). Our themes were common across the five countries, suggesting that hegemonic masculinity influences and constrains young men's behaviour in Northern (England), Southern (Italy), Eastern (Bulgaria), Slavic (Slovenia) and Russian-language (Latvia) regions of Europe. We did note some secondary themes which were more country-specific. For example, young women in Latvia highlighted the role of alcohol at parties in facilitating the sexual harassment of young women; they also drew attention to popular Latvian songs in objectifying women and potentially influencing young men's practices towards their female peers. Our young people in Bulgaria suggested that young women were expected to accept men's sexual advances, while in the UK young women who rejected male attention or were perceived to spend too much time with other young women were often denounced as 'frigid' or 'lesbian' by young men. In Italy the theme of 'sexting' was particularly strong, while in Slovenia there was an emphasis on young men shouting 'abusing' names at each other for 'fun'. These in-country inflections to hegemonic masculine 
enactments require further exploration. Since our data conflict with more positive analyses of young masculinities, for example within inclusive masculinity theory (e.g. Anderson, 2009), which indicate the growth of more caring, tolerant and relational orientations among boys and young men, more work is also required to specify the conditions, cultures and contexts in which more progressive versions of young masculinity can flourish.

The inclusion of young women's voices within our project is noteworthy since much research on masculinities tends to focus exclusively on male perspectives. While there was much criticism of young men for their sexual harassment and homophobia, the young women also perceived a resilient and relaxed orientation which they viewed positively. Further research is required to examine young masculinities from the point of view of female peers in order to compare with young men's own accounts and to identify potential misunderstandings, points of connection and potential for productive dialogue so that more respectful interactions and relationships between young men and women may be fostered. We would also propose further research with young people from the countries included in our project and other countries within Europe - and beyond - to encompass a greater range of discourse and practice pertaining to young masculinities; such work would heed Connell's (2016) call to investigate masculinities in the Global South.

Finally, we recommend interventions in schools and other youth-based settings to challenge 'toxic' masculinities and sexual bullying; in fact, our project has developed a programme designed to be used by young people, and the adults working with them, to do just that (see:WEBSITE BLINDED). One of our recommendations concerns hosting classes and workshops with young people designed to raise awareness of and challenge gender stereotypes which inform and sustain sexual bullying important because our young people were unsure about the nature, scope and impact of mundane gendered harassment. Young men in particular often did not anticipate the potential harm caused by their 'heteronormative cruelties', prone to construing these as innocuous and mundane (Carrerra-Fernandez et al., 2016). Such interventions could take place within timetabled citizenship classes, for example Personal, Social and Health Education classes in the UK. Our intervention is in keeping with other endeavours designed to work with young men (and young women) to rethink masculinity/femininity norms and practices (e.g. The Good Lad Initiative in the UK: www.goodladworkshop.com/). In sum, the data and resources generated by our project highlight ongoing heteronormative pressures and constraints on young people's identities, interactions and relationships while offering insights and resources for reworking young masculinities in particular.

\section{References}

Adams Tucker, L. \& Govender, K. (2017) 'Sticks and stones': masculinities and conflict spaces, Gender and Education, 29:3, 352-368

Anderson, E. (2009) Inclusive Masculinity: The changing nature of masculinities. Basingstoke: Palgrave MacMillan.

Atkinson, M. (2010) Deconstructing Men and Masculinities. Toronto: Oxford University Press.

Bartholomaeus, C. (2013) Colluding with or challenging hegemonic masculinity?, Australian Feminist Studies, 28:77, 279-293

Braun, V. and Clarke, V. (2006) Using thematic analysis in psychology, Qualitative Research in Psychology, 3(2): 77. 
Bridges, T. \& Pascoe, C.J. (2014) Hybrid masculinities: New directions in the sociology of men and masculinities, Sociology Compass, 8(3): 246-258.

Carrera-Fernández, MV., Lameiras-Fernández, M. \& Rodríguez-Castro, Y. (2018) Performing intelligible genders through violence: bullying as gender practice and heteronormative control, Gender and Education, 30:3, 341-359

Connell, R.W. (2016) Masculinities in global perspective: hegemony, contestation, and changing structures of power. Theory \& Society 45(4): 303-318.

Connell, R. W. (1995) Masculinities. Cambridge, UK: Polity.

Connell, R. W. \& Messerschmidt, J. W. (2005) Hegemonic masculinity rethinking the concept. Gender \& Society, 19(6): 829-859.

Cook, J. \& Hasmath, R. (2014) The discursive construction and performance of gendered identity on social media. Current Sociology, 62(7): 975-993.

De Boise, S. \& Hearn, J. (2017) Are men getting more emotional? Critical sociological perspectives on men, masculinities and emotion, The Sociological Review, 1-18.

Dempster, S. (2011) I drink, therefore I'm man: gender discourses, alcohol and the construction of British undergraduate masculinities, Gender and Education, 23(5): 635-653.

de Visser, R. O. \& McDonnell, E. J. (2013) 'Man points': Masculine capital and young men's health. Health Psychology, 32(1): 5-14.

De Ridder, S. \& Van Bauwel, S. (2015). The discursive construction of gay teenagers in times of mediatization: Youth's reflections on intimate storytelling, queer shame and realness in popular social media places. Journal of Youth Studies, 18(6): 777-793.

Dumas, Graham \& Wells (2014) The Company They Keep: Drinking Group Attitudes and Male Bar Aggression, Journal of Studies on Alcohol and Drugs, 447-451.

Flood, M. (2010). "Young Men Using Porn". In Boyle, Karen. Everyday Pornography. London, New York: Routledge. (pp. 164-178).

Frosh, S., Phoenix, A. \& Pattman, R. (2001) Young Masculinities: Understanding Boys in Contemporary Society. London: Sage.

Gough, B.,Hall, M. \& Seymour-Smith, S. (2014) Straight guys do wear make-up: Contemporary masculinities and investment in appearance, in S. Roberts (Ed) Debating Modern Masculinities: Change, Continuity, Crisis?. Basingstoke: Palgrave.

Hall, M., Gough, B., Seymour-Smith, S. (2012) 'I'm METRO, NOT gay', a discursive analysis of men's make-up use on YouTube, Journal of Men's Studies, 20 (3), 209-226.

Hanlon, N. (2012) Masculinities, Care and Equality: Identity and Nurture in Men's Lives. Basingstoke, UK: Palgrave Macmillan.

Harger, B. (2016) You say bully, I say bullied: School culture and definitions of bullying in two elementary schools. In: Vol. 20. Sociological Studies of Children and Youth (pp. 93-121).

Ingram, N. \& Waller, R. (2014) Degress of masculinity: Working and middle-class undergraduate students' constructions of masculinity in contemporary Britain, in S. Roberts (Ed) Debating Modern Masculinities: Change, Continuity, Crisis?. Basingstoke: Palgrave. 
Kehler, M. \& Atkinson, M. (2015) The Space Between: Negotiating Male Subjectivities in Physical Education Research. International Journal of Men's Health 14(3): 259-272.

Marwick, A. \& boyd, d. (2014) 'It's just drama': teen perspectives on conflict and aggression in a networked era, Journal of Youth Studies, 17:9, 1187-1204, DOI: 10.1080/13676261.2014.901493

McCormack, M. (2012) The Declining Significance of Homophobia: How Teenage Boys are

Redefining Masculinity and Heterosexuality. Oxford, UK: Oxford University Press.

Morris, M. \& Anderson, E. (2015) 'Charlie Is So Cool Like': Authenticity, Popularity and Inclusive Masculinity on YouTube, Sociology, 1-18.

O'Neill, R. (2014) Whither Critical Masculinity Studies? Notes on Inclusive Masculinity Theory, Postfeminism, and Sexual Politics, Men \& Masculinities, 1-21.

Pascoe, C.J. (2013) “Notes on a Sociology of Bullying: Young Men's Homophobia as Gender Socialization," QED: A Journal in GLBTQ Worldmaking, Inaugural Issue, 87-104.

Powell, A., Henry, N. \& Flynn, A. (2018) Image-based sexual abuse, in W. DeKeseredy and M. Dragiewicz (Eds), Routledge Handbook of Critical Criminology (2e), pp. 305-15. Routledge: London.

Quayle, M., Lindegger, G., Brittain, K., Nabee, N. \& Cole, C. (2018) Women's Ideals for Masculinity Across Social Contexts: Patriarchal Agentic Masculinity is Valued in Work, Family, and Romance but Communal Masculinity in Friendship, Sex Roles, 78: 52-66.

Renold, E, Bragg, S, Jackson, C \& Ringrose, J. (2017). How gender matters to children and young people living in England. Project Report. Cardiff University.

Renold, E. (2013) Boys and girls speak out: A qualitative study of children's gender and sexual cultures (aged 10-12). Cardiff University.

Ringrose, J. \& Renold, E. (2010). Normative cruelties and gender deviants: the performative effects of bully discourses for girls and boys in school. British Educational Research Journal, 36(4), 573-596.

Ringrose, J. \& Harvey, L. (2015) Boobs, back-off, six packs and bits: Mediated body parts, gendered reward, and sexual shame in teens' sexting images, Continuum: Journal of Media \& Cultural Studies, 29(2): 205-17.

Rivers, I., Chesney, T. \& Coyne, I.J. (2011). Cyber-bullying. In C.P. Monks \& I.J. Coyne (Eds.) Bullying in different contexts (pp. 211-230). Cambridge: Cambridge University Press.

Swain, J. 2006. "Reflections on Patterns of Masculinity in School Settings." Men and Masculinities 8 (3): 331-349.

Ward, M. (2015). From Labouring to Learning, Working-class Masculinities, Education and Deindustrialization. Palgrave Macmillan.

Yépez-Tito, P., Ferragut, M. \& Blanca, MJ. (2019) Prevalence and profile of sexting among adolescents in Ecuador, Journal of Youth Studies, 22:4,505-519 